\title{
Pemimpin Indonesia Masa Depan
}

\author{
T. Jacob
}

Leader means the head of government, the members of cabinet, those of executive, judicative, legislative and the leaders of political parties. Departing from afore explanation, it is clear that the leader that Indonesian people need is the leader who can solve the problems of this nation. As leader, he or she should have collective and future oriented. The leader must have decisional competence, tolerant and morality attitude. Besides, acceptability of the leader denotes political basic and the cultural foundation.

Yan ang dimaksud dengan pemimpin adalah kepala pemerintahan, anggota-anggota kabinet, pejabat-pejabat tinggi eksekutif, legislatif dan yudikatif, serta ketua-ketua partai-partai politik, sedangkan yang dimaksudkan dengan masa sesudah pemilihan umum 2004 sampai $10-15$ tahun kemudian. Masa ini penting dalam menghadapi simpang jalan menuju dekomposisi (pembusukan) total, bangkrut dan kolapsnya negara Indonesia dalam bentuknya yang sekarang, atau menuju risorgimento (kebangkitan kembali) dengan kulit baru dan isi baru yang bebas dari defek moral, patologi sosial, disrupsi jaringan ekonomis dan pudarnya kedaulatan politik, yang berakibat disintegrasi bangsa, hilangnya kohesi dalam dan adhesi antara lapisan-lapisan sosial-ekonomiș, lumpuhnya hukum (undang-undang banyak, tetapi keadilan tidak ada) dan meningkatnya kriminalitas, maksiat serta perbuatan haram dan dosa: Untuk mencegah hal itu kesempatan yanig:baik adalah mengadakan pemilihan umum 2004 yang diharapkan akan berhasil positif.
Untuk menggambarkan tokoh pemimpin masa depan yang baik, kita harus dapat membayangkan masa depan yang bagaimana yang akan kita hadapi. Banyak sekali syarat yang diajukan orang bagi pemimpin yang dinginkan, sehingga tidak mungkin dipenuhi oleh seorang manusia biasa. Jika kita pakai satu kriterium saja, maka pemimpin yang dikehendaki adalah yang bonafide (dapat diandalkan), jangan yang malafide. Jika kita jabarkan sedikit, maka pemimpin idaman adalah yang mempunyai kompetensi humaniter, intelektual dan desisional (bijak dalam membuat keputusan politis). Terliput dalam kreteria ini pemimpin memiliki pendidikan dan alfabetisma (dalam arti yang luas), integritas moral serta kemampuan memilih kemampuan mengkoordinasi pembantupembantu yang sehaluan seirama.

\section{Ciri-ciri Masa Depan}

Secara singkat masa depan. jangka dekat dan sedang akan terpengaruh oleh teknologi, terutama dalam bidang informasi 
can komunikasi, disamping kemajuan dalam industri. Sebagian dari kemajuan itu akan menguntungkan negeri-negeri kurang berkembang, dan sebagian lagi sebaliknya, yang dapat menimbulkan kontras/mencolok dan dominasi pihak yang kuat atas yang lemah. Sumber daya alam dan kekuatan demografis kurang berarti dibandingkan dengan penguasaan informasi serta kekuatan ekonomi dan militer. Informasi tak mengenal batas negara, demikian juga globalisma ekonomi dan jangkauan sistem persenjataan. Hukum-hukum perang, baik ius in bello akan berbeda dari zaman perang konvensional, dimana waktu untuk bereaksi tidak krusial dan jarak membatasi gerak. Sistem pertahanan modern dengan demikian banyak berubah dan negaranegara kecil harus berjuang, agar perdamaian menjadi tiang raja dalam hubungan internasional. Pemimpin diplomasi harus kuat dan inovatif.

Tetangga-tetangga kita akan mengalami kemajuan pesat, antara lain China dan India, yang akan memegang peranan penting dalam geopolitik Asia Tenggara, Timur dan Selatan. Kita harus siap menghadapi konstelasi politik baru, dengan memperhatikan Jepang, Vietnam, Thailand, Malaysia dan Pakistan. Dari luar wilayah, Amerika-Inggris, Australia-Selandia Baru, dan Uni Eropa akan mempertahankan pengaruhnya agar berimbang. Pemimpin kita harus mengantisipasi hal ini.

Indonesia sebagai arkipel adalah negara laut dan selat, yang mudah dilalui kapal asing dengan bebas. Kita harus siaga dan waspada pada pulau-pulau Sempadan (perbatasan), pulau-pulau yang akan tenggelam oleh pemanasan bumi, pantaipantai kota besar yang akan lenyap, dan kekayaan laut yang dinikmati orang lain atau rusak dan musnah oleh pariwisata dan penangkapan ikan berlebihan (overfishing) atau perikanan intensif. Pemimpin kita harus memperhatikan keutuhan teritorial.

Ekosistem global akan terus terganggu oleh usaha-usaha ekonomi eksploitatif, pencemaran, perubahan kerak bumi oleh kegiatan antropogeologis dalam skala, kecepatan dan luas yang makin besar. Sebagian (besar) rakyat tidak ikut serta dalam mengolah dan menikmati pengubahan ekosistem itu. Jadi pemimpin harus menjaga lingkungan untuk diwariskan serta mendahulukan kepentingan dan kesejahteraan rakyat.

Kecerdasan rakyat kita makin jauh ketinggalan dari rakyat negeri-negeri maju dan usaha pendidikan masih terus terabaikan, karena pemimpin-pemimpin dalam realisasi pembangunan tidak melihat pentingnya. Akibatnya kita terus menjadi pihak yang dirugikan dalam kompetisi dan kooperasi internasional dengan menempati lapangan kerah biru dalam pembagian kerja global. Exodus tenaga kerja kita keluar desa dan migrasi ke pusat-pusat pertumbuhan ekonomis di luar negeri akan berlangsung terus dalam kondisi demikian. Pemimpin kita tidak dapat terus mengabaikan usaha pencerdasan bangsa dan menjamin hak kerja bagi warga negaranya.

Dalam interdependensi yang makin meningkat dan makin asimetris, Swadeshi (memakai produk negeri sendiri) dan swasta (berdiri sendiri) sukar dipraktekkan, sehingga ketergantungan kita bertambah besar, padahal negara-negara besar dapat hidup autarkis, kecuali dalam minyak bumi, kopi, coklat, pisang dan rempah-rempah, tetapi harganya tidak dapat ditentukan sendiri oleh negara produsen, kecuali ganja dan candu. Kita mempunyai kedudukan tanggung sebagai negeri agraris, manufaktur maupun jasa. Maka posisi global kita harus menjadi fokus perhatian pemimpin. 
Jika tidak ada terobosan oleh pemimpin yang berwibawa, berani dan mempunyai visi futuristik, peranan kita sebagai daerah tapi akan tetap dirugikan oleh setrum yang kuat dan maju. Visj internasional pemimpin kita harus saling menyokong dengan visi nasional.

\section{Pemimpin yang Didambakan}

Berangkat dari uraian di atas, maka Pemimpin yang dapat diandalkan memecahkar masalah-masalah kita yang perenial, harus tidak egoištis, tetapi berjuang untuk kepentingan kolektif, harus berorientasi ke depan (future-oriented), tidak terpukau oleh kegemilangan masa lampau atau kepentingan saat ini, dan dapat menjaga harmoni dan ekuilibrium antara pusat dan tepi, antara lapisan atas dan bawah, antara berbagai agama, dan transkultural. Bagaimanapun juga persatuan Indonesia harus berdiri di atas multikulturalisme mengingat deversitas ekologis dan geografis, linguistik dan etnik. Pemimpin harus mengenal bangsa dan tanah air Indonesia, tidak mempunyai wawasan yang sempit.

Salah satu kekurangan kita yang berlanjut adalah tidak sesuainya penghasilan dan pengeluaran. Ini terjadi dalam pemerintahan dan birokrasi, serta di kalangan pejabat dan masyarakat. Dalam hal ini peletakan prioritas masih dipengaruhi berat oleh masa kini, kurang memperhatikan generasi yang akan datang. Warisan jangan mengandung beban yang berat dalam pembayaran hutang dan kerusakan ekologis bagi angkatan masa depan.

Sebagai pemimpin seorang harus memiliki decisional competence tegas dan berani karena benar, tidak bimbang dan ragu, baik di dalam maupun di luar kandang. Pemimpin harus berwibawa di dalam dan di luar negeri; di dalam negeri sebaiknya pemimpin memiliki karisma yang masih diperlukan oleh rakyat kita dalam tahapan perkembangannya sekarang. Untuk berani seseorang harus mempunyai disiplin moral dan legal, tidak tergiur mempergunakan kekuasaan untuk melanggar aturan.

Selanjutnya seorang pemimpin harus memperlihatkan toleransi yang wajar terhadap perbedaan, tetapi tidak terhadap penyimpangan dan pelanggaran. Empati dan simpati terhadap bencana, derita dan kesusahan yang dialami rakyat adalah syarat untuk dipatuhi dan dihormati. Pemimpin harus dihormati, tidak hanya ditakuti, meskipun ketakutan meninggalkan kesan sampai lama.

Akseptabilitas seorang pemimpin, programnya atau ideologinya sangat banyak menolong keberhasilannya. Akseptabilitas kadang-kadang berbeda dengan kebenaran, tetapi kedua-duanya adalah ilmiah. Kebenaran yang tidak dapat diterima sebagai kebijakan tidak banyak gunanya untuk periode tersebut. Akseptabilitas merupakan basis politis dan kultural dalam implementasi kebijakan; adalah tidak ilmiah kalau hal ini tidak diperhatikan.

Akhir kata, seorang pemimpin harus menaruh hormat pada Tuhan, rakyat, hukum, moral dan dirinya sendiri. Jika pemimpin tidak menghargai martabatnya, bagaimana orang dapat menghormatinya.

\section{Daftar Pustaka}

Alter, Peter. 1994, Nasionalism, $2^{\text {nd }}$ ed. London: Edward Arnold.

Delannoi, Gil, 1995, Le nasionalism et la catalyse ideologique, dalam Serge Cordellier (coord): Nations et Nationalismes, PP. $39-47$. La Decouverte, Paris 
Gretman, Roy, \& Rieff, David 2000, Kriegsverbrechen. DVA, Stuttgart.

Hansen, James, 2004, Defusing the global warming time bomb. Scient. Am. 290(3): $40-49$.

Herzfeld, Michael, 2000, Le revanche de la communaute locale: La globalisation de l'heterogeneite locale, dalam Michael Elbaz \& Denise Helly (dirs): Mondialisation, Citoyennete et Multiculturalisme, pp. 69-77. Les Presses de l'Universite Laval.

Jacob, Teuku, 2004, Tragedi Negara Kesatuan Kleptokratis, Jakarta: Yayasan Obor.

2004, Tenaga Alam Raya, jil. 1-2. Yogyakarta:B.P. Kedaulatan Rakyat.

2004, Manusia Makhluk Gelisah. Surakarta : UMS University Press.
Martin, Hans-Peter, \& Schumann, Harold 1998. Die Globalisierungsfalle: Der Anggriff auf Demokratie und Wohlstand. Hamburg: Rohwohlt, Reinbek bei .

Pihlajamaa, Loes. 2000, Biologie is geschiedenis and geschiedenis is biologie. Jongieren met Kennis, pp. 19-33. Limburg:HOVO Universiteit Masstricht.

Plihon, Dominique, 1999, Tyrannie de la globalisation, dalam Bernard Cassen, Liem Hoang-Ngoc \& Pierre-Andre Lambert (coord.): Attac Contre la Dictature des Marches, pp.15-22. Paris:La Dispute.

Stock, Gregory, 2003 ,Redesigning Humans. Boston: Houghton Mifflin Company. 